\title{
New Estimates of the Available Potential Energy in the World Ocean
}

\begin{abstract}
Abraham H. Oort, ${ }^{1}$ Stephen C. Ascher, ${ }^{2}$ Sydney Levitus, ${ }^{1}$ and José P. Peixóto ${ }^{3}$
On the basis of extensive global data sets the total amounts of internal, potential, latent, and kinetic energy in the world oceans and atmosphere are estimated and compared for annual mean and seasonal conditions. Next, an expression for the available gravitational potential energy in the oceans is derived. The computed amounts of zonal mean and transient eddy available potential energy and the amount of kinetic energy present in the oceans are found to be much smaller (at least 1 order of magnitude) than those in the atmosphere. Because of the sparseness of directly measured subsurface values, the estimates of the kinetic energy and the transient eddy available potential energy were obtained by extrapolation from the corresponding values measured at the ocean surface. The fact that relatively large density variations are found only in the upper few hundred meters of the oceans and the greater stability of the oceans are the basic reasons for the generally small values of the potential and kinetic energy in the oceans compared with those in the atmosphere.
\end{abstract}

\section{INTRODUCTION}

Large amounts of energy are present in the atmosphere and oceans, but generally they do not appear to participate in the energy cycle of the Earth's fluid envelope. In fact, most of the energy seems to be stagnant, dead, and unavailable for conversion into kinetic energy. The issue of how to separate the available from the unavailable energy has been discussed extensively in the context of the atmosphere, notably by Margules [1903] for individual storms and by Lorenz $[1955,1978]$ in a generalized form for the global atmosphere. In fact, Lorenz' box diagrams for the energy cycle (see Figure 1) have become a standard means of characterizing the flow or circulation regime not only in the Earth's atmosphere but also in a great variety of other geofluid systems, such as the atmospheres of the other planets, rotating dishpan experiments, and the Gulf Stream system, to name only a few.

In the present paper we will emphasize the contributions of the oceans to the available energy in the climatic system and compare them to those of the atmosphere as determined in earlier work [Oort and Peixóto, 1973]. Because the mass of the oceans and their heat capacity are so large compared with those of the atmosphere, the total amount of potential plus internal energy is about a factor of 1000 larger in the oceans than in the atmosphere. Therefore one might expect the available potential and internal energy also to be much greater in the oceans than in the atmosphere. However, based on order of magnitude estimates the kinetic energy is very much smaller in the oceans than in the atmosphere. In a sense there is a contradiction here. In spite of the almost unlimited supply of total energy in the oceans, a minute fraction, only one part in a billion $\left(10^{9}\right)$, shows up in the form of kinetic energy. Thus the question arises: Is the available potential plus internal energy in the oceans also proportionally smaller than that in the atmosphere, or is it much larger as we originally expected? This is an important question to address, and while working

${ }^{1}$ Geophysical Fluid Dynamics Laboratory, NOAA, Princeton University, Princeton, New Jersey.

${ }^{2}$ Department of Geology and Geophysics, Yale University, New Haven, Connecticut.

${ }^{3}$ University of Lisbon, Lisbon.

Copyright 1989 by the American Geophysical Union.

Paper number $88 \mathrm{JC} 04170$.

0148-0227/89/88JC-04170\$05.00 toward an answer we may discover new clues as to the relative roles of the oceans and atmosphere in the climatic system.

In this paper we will not concentrate on the role of the oceans in storing and releasing heat. This crucial function of the oceans in moderating the Earth's climate is well established. Nor will we discuss here the role of the oceans in storing heat from one year to the next, although it is thought to be one of the primary "causes" of short-term climatic change. In summary, we will limit our discussion mainly to the long-term mean climate and to the relative roles the oceans and atmosphere play in it.

\section{Formulation}

\subsection{Available Potential Energy}

in the Atmosphere

In the atmosphere the internal energy IE and potential energy PE are given by the following expressions

$$
\begin{gathered}
\text { IE }=\iiint \rho c_{v} T d x d y d z \\
\mathrm{PE}=\iiint \rho g z d x d y d z \cong \iiint \rho R T d x d y d z
\end{gathered}
$$

Where $\rho$ is the density, $c_{v}$ is the specific heat at constant volume, $R$ is the gas constant for dry air, $T$ is the temperature (in degrees Kelvin), $g$ is the acceleration due to gravity, and $z$ is the height above sea level.

Following Lorenz [1955], we will combine the internal and potential energy. Thus the total potential energy can be written as

$$
\mathrm{TPE}=\iiint \rho c_{p} T d x d y d z
$$

where $c_{p}=c_{v}+R=1005 j \mathrm{~kg}^{-1}{ }^{\circ} \mathrm{K}^{-1}$ is the specific heat at constant pressure.

The available potential energy was then defined by Lorenz as the difference between the total potential energy in the actual atmospheric state and the one in the reference or dead state, where the isentropic surfaces are horizontal. The reference state can be reached in a thought experiment by redistributing the mass adiabatically.

Thus

$$
P=\iiint \rho c_{p} T d x d y d z-\iiint \rho_{r} c_{p} T_{r} d x d y d z
$$




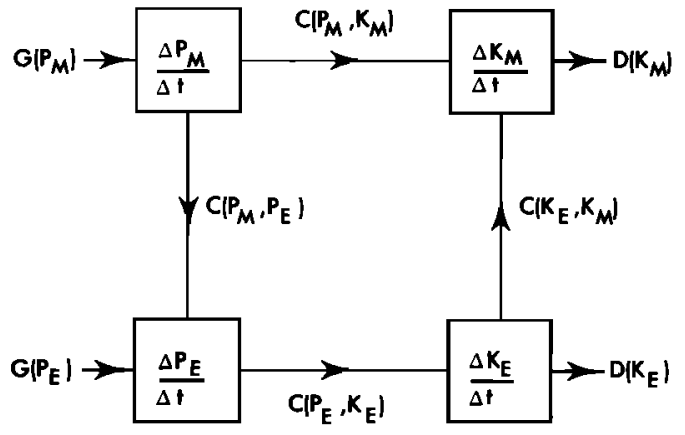

Fig. 1. Schematic box diagram for the energy cycle in the atmosphere showing the rates of generation $G(\mathrm{~A})$, conversion $C(\mathrm{~A}, \mathrm{~B})$ and dissipation $D(B)$. A similar diagram can be constructed for the world ocean where the generation terms are the atmospheric differential heating and evaporation-minus-precipitation at the ocean surface as far as they affect the density variations. A new term for the oceans will be the wind driving at the surface leading to an additional source of kinetic energy.

where $\rho_{r}$ and $T_{r}$ are the density and temperature in the reference state, respectively, and are only a function of pressure. Under certain assumptions, such as that the isentropic surfaces are not too steeply inclined with respect to the horizontal, Lorenz [1955] was able to derive the so-called approximate formulation.

$$
P=c_{p} \frac{\gamma}{2} \int\left(T^{2}-\tilde{T}^{2}\right) d m
$$

Here $\tilde{T}=\tilde{T}(p)$ is the global mean temperature (in degrees Kelvin) over a constant-pressure surface (the reference temperature $\left.T_{r}\right), \gamma=\gamma(p)$ is an inverse measure of the global mean static stability

$$
\gamma=\left(\Gamma_{d} / \tilde{T}\right)\left(\Gamma_{d}-\tilde{\Gamma}\right)^{-1}
$$

$\Gamma_{d}=-1 \% / 100 \mathrm{~m}$ is the dry adiabatic lapse rate and $\tilde{\Gamma}$ is the global mean lapse rate, and $d m=\rho d x d y d z$ a mass element.

Expression (5) has been widely used in studies of the general circulation of the atmosphere. The integrand is a measure of the variance of the temperature on an isobaric surface. As expected, when the variance in temperature and the horizontal temperature gradients are large, the available potential energy is also large. Further, when the mean static stability decreases, the available potential energy tends to increase.

\subsection{Available Potential Energy in the Oceans}

In the oceans the internal and potential energy can be given by expressions similar to (1) and (2).

$$
\begin{aligned}
\mathrm{IE} & =\iiint \rho c_{0} T d x d y d z \\
\mathrm{PE} & =\iiint \rho g z d x d y d z
\end{aligned}
$$

where all quantities refer here to the oceans, e.g., $c_{0}=4187 \mathrm{~J}$ $\mathrm{kg}^{-1}{ }^{\circ} \mathrm{K}^{-1}$ is the specific heat at constant pressure for ocean water, and $\rho$ is the in situ density.

There is some question about what value one should use for $z$ in calculating the potential energy from (7). In the case of the atmosphere it was natural to refer the potential energy to mean sea level. On the other hand, for the oceans the choice is not so obvious. Among some theoretical options for the reference level, such as the equipotential surface corresponding to the greatest ocean depth, we chose the equipotential surface of the mean ocean depth of $-3740 \mathrm{~m}$ (see Table 1) as a reference level. Another complication is that in the case of the oceans we cannot combine the potential and internal energy into a form similar to (3). The reason for this is the complex equation of state relating density, temperature, salinity, and pressure in seawater. Nevertheless, we can give a formal expression for the available potential energy in a way similar to that given in (4) by defining a thermodynamic reference state in which the density surfaces are horizontal.

Some attempts [e.g., Reid et al., 1981] have been made to formulate and evaluate the available potential and internal energy in the oceans from first principles. Reid et al. [1981] concluded that the available potential energy is the dominant term and that the available internal energy can only contribute 10 to $20 \%$ to the total. Counterintuitively and in contrast to what is observed in the atmosphere, Reid et al. [1981] find a contribution of the internal energy that is negative. These authors attribute this fact to the different behavior of the compressibility as a function of temperature in the oceans and atmosphere.

Because of the difficulties and uncertainties in the formulation of available internal energy, we will restrict our discussion here to the available gravitational potential energy. This last quantity can be formulated and computed in a relatively straightforward manner, and according to Reid et al. [1981], it constitutes the dominant term in the total potential energy.

The available gravitational potential energy is thus given by

$$
P=\iiint \rho g z d x d y d z-\iiint \rho_{r} g z_{r} d x d y d z
$$

\begin{tabular}{|c|c|c|c|}
\hline & $\begin{array}{l}\text { Surface Area, } \\
10^{14} \mathrm{~m}^{2}\end{array}$ & $\underset{\text { mean Depth, }}{\text { Me }}$ & $\begin{array}{l}\text { Mass, } \\
10^{20} \mathrm{~kg}\end{array}$ \\
\hline \multicolumn{4}{|c|}{ Atmosphere } \\
\hline Northern hemisphere & 2.56 & $\sim 24,000^{*}$ & $0.0246 \dagger$ \\
\hline Southern hemisphere & 2.56 & $\sim 24,000^{*}$ & $0.0245^{*}$ \\
\hline Global & 5.12 & $\sim 24,000^{*}$ & $0.0491^{*}$ \\
\hline \multicolumn{4}{|c|}{ Ocean } \\
\hline Northern hemisphere & 1.47 & 3,614 & 5.50 \\
\hline Southern hemisphere & 2.05 & 3,830 & 8.16 \\
\hline Global & 3.52 & 3,740 & 13.66 \\
\hline Atlantic & 1.00 & 3,406 & 3.54 \\
\hline Pacific & 1.77 & 3,928 & 7.22 \\
\hline Indian & 0.75 & 3,745 & 2.91 \\
\hline
\end{tabular}

After changing from the $(x, y, z)$ to the $(x, y, \rho)$ coordinate

TABLE 1. Some Physical Characteristics of the Atmosphere and of the Breakdown of the World Ocean used in the Present Study

*Vertical integrations in the atmosphere were performed in pressure coordinates between the Earth's surface and the 25-mbar level, giving a weight of 0.75 to the 1000 -mbar value and weights of 1.00 to the $950,900,850,800, \ldots$, and 50 -mbar levels. All grid point values below the mountains were given a weight of zero.

†Using actual surface pressure analyses, Oort [1983, p. 96] found for the northern hemisphere, southern hemisphere, and globe the total mass values of $0.0257,0.0258$, and $0.0515 \times 10^{20} \mathrm{~kg}$. 
system, we may also write

$$
\begin{aligned}
P & =\frac{1}{2} g \iiint z^{2} d x d y d \rho-\frac{1}{2} g \iiint z_{r}^{2} d x d y d \rho \\
& =\frac{1}{2} g \iiint\left(z^{2}-z_{r}^{2}\right) d x d y d \rho
\end{aligned}
$$

or

$$
P=\frac{1}{2} g \iiint\left(z-z_{r}\right)^{2} d x d y d \rho
$$

Substituting next the global mean height over a constantdensity surface $\tilde{z}=\tilde{z}(\rho)$ for the reference height $z_{r}$, and using the observed fact that the horizontal gradients in density are much smaller than the vertical gradients, we can finally derive

$$
P=-\frac{1}{2} g \iiint(z-\tilde{z})^{2} \frac{\delta \tilde{\rho}}{d z} d x d y d z
$$

Since we are considering vertical displacements, we are using here the vertical gradient of the local potential density $-\delta \tilde{\rho} / d z$ [see Neumann and Pierson, 1966, p. 139] instead of the vertical gradient of the in situ density $-d \tilde{\rho} / d z$ as a measure of the stability in our calculations of the available potential energy.

As an alternative to (9), we can use the departures of the local density from the global mean density over a constantheight surface, $\tilde{\rho}=\tilde{\rho}(z)$, and write

$$
P=-\frac{1}{2} g \iiint \frac{(\rho-\tilde{\rho})^{2}}{\delta \tilde{\rho} / d z} d x d y d z
$$

Similarly, as was done before for the atmosphere in terms of the variance of temperature over an isobaric surface, the integrand of the available gravitational potential energy can now be expressed in terms of the variance of height over an isosteric surface (equation (9)) or the variance of density over a constant-depth surface (equation (10)) weighted by the mean stability factor $(-\delta \tilde{\rho} / d z)$. The actual calculations will be carried out using (10).

\subsection{Kinetic Energy in the Atmosphere and Oceans}

The kinetic energy integrals have basically the same form in both the atmosphere and oceans:

$$
K=\iiint \frac{1}{2} \rho|\mathbf{c}|^{2} d x d y d z
$$

where $\mathbf{c}$ is the vector wind or current speed with components $\mathrm{c}=(u, v, w)$. Because the vertical velocities $w$ are comparatively small, we can approximate (11) by

$$
K=\iiint \frac{1}{2} \rho\left(u^{2}+v^{2}\right) d x d y d z
$$

\subsection{Breakdown of the Energy Into Zonal Mean and Eddy Components}

A breakdown of the energy into different components in space and time often provides new insights into the energetics of the system. Following Lorenz' [1955] approach as expanded by Oort [1964], we will separate the energy into zonal mean, stationary eddy, and transient eddy components. To accomplish this, we will use the following notations

$$
A=\langle A\rangle+A^{\prime}
$$

where $\langle A\rangle$ is the time mean (i.e., annual mean) value of $A$ and $A^{\prime}$ is the departure from the time mean so that $\left\langle A^{\prime}\right\rangle \equiv 0$, and

$$
A=[A]+A^{*}
$$

where $[A]$ is the zonal mean value of $A$ and $A^{*}$ is the departure from the zonal mean, so that $\left[A^{*}\right] \equiv 0$. Since the time averages in this paper are generally computed over 1 or more years, the transient eddy statistics presented will include the contributions from all eddies with time scales of less than 1 year, such as the seasonal variation as well as synoptic and mesoscale eddies. Thus we find for the available potential energy in the atmosphere, from (5),

$$
\begin{aligned}
P= & P_{M}+P_{E}=P_{M}+P_{S E}+P_{T E} \\
=c_{p} \frac{\gamma}{2} \int([\langle T\rangle]-\langle\tilde{T}\rangle)^{2} d m & \\
& \quad+c_{p} \frac{\gamma}{2} \int\langle T\rangle^{* 2} d m+c_{p} \frac{\gamma}{2} \int\left\langle T^{\prime 2}\right\rangle d m
\end{aligned}
$$

The three components in (15) are the zonal and time mean available potential energy $\boldsymbol{P}_{M}$, the stationary eddy available potential energy $P_{S E}$, and the transient eddy available potential energy $P_{T E}$

In analogy to the atmospheric case, we can write for the available gravitational potential energy in the oceans using (10):

$$
\begin{aligned}
P= & P_{M}+P_{E}=P_{M}+P_{S E}+P_{T E} \\
= & -\frac{1}{2} g \iiint([\langle\rho\rangle]-\langle\tilde{\rho}\rangle)^{2}(\delta\langle\tilde{\rho}\rangle / d z)^{-1} d x d y d z \\
& -\frac{1}{2} g \iiint\langle\rho\rangle^{* 2}(\delta\langle\tilde{\rho}\rangle / d z)^{-1} d x d y d z \\
& -\frac{1}{2} g \iiint\left\langle\rho^{\prime 2}\right\rangle(\delta\langle\tilde{\rho}\rangle / d z)^{-1} d x d y d z
\end{aligned}
$$

Finally, for the kinetic energy we find from (12)

$$
\begin{aligned}
K= & K_{M}+K_{E}=K_{M}+K_{S E}+K_{T E} \\
= & \iiint \frac{1}{2} \rho\left([\langle u\rangle]^{2}+[\langle v\rangle]^{2}\right) d x d y d z \\
& +\iiint \frac{1}{2} \rho\left(\langle u\rangle^{* 2}+\langle v\rangle^{* 2}\right) d x d y d z \\
& +\iiint \frac{1}{2} \rho\left(\left\langle u^{\prime 2}\right\rangle+\left\langle v^{\prime 2}\right\rangle\right) d x d y d z
\end{aligned}
$$

where $K_{M}$ denotes the time and zonal mean kinetic energy, $K_{S E}$ is the stationary eddy kinetic energy, and $K_{T E}$ is the transient eddy kinetic energy.

To see the interconnectedness and relations between the different components, it is often useful to study the components in the context of an energy box diagram of the form shown in Figure 1, where the stationary and transient eddy contributions have been combined (for simplicity) and where $G(A)$ indicates a generation process of component $\mathrm{A}, C(\mathrm{~A}, \mathrm{~B})$ is a conversion process from component $A$ to component $B$, and $D(B)$ a dissipation process of component $B$.

In the present paper we will not discuss the energy generation, transformation and dissipation processes but will leave this for a future paper. We will only attempt to estimate the actual energy amounts contained in the four boxes and their relative magnitude in the atmosphere and oceans. 
TABLE 2. Annual Mean Energy Content of the Atmosphere and its Seasonal Range (January-July) Based on 1963-1973 Rawinsonde Analyses [Oort, 1983]

\begin{tabular}{|c|c|c|c|c|c|c|c|c|c|}
\hline & \multicolumn{3}{|c|}{ Energy Integrals, $10^{22} \mathrm{~J}$} & \multicolumn{3}{|c|}{ Energy per Unit Area, ${ }^{*} 10^{7} \mathrm{~J} \mathrm{~m}^{-2}$} & \multicolumn{3}{|c|}{$\begin{array}{c}\text { January-July Energy Differences per } \\
\text { Unit Area, } 10^{7} \mathrm{~J} \mathrm{~m}^{-2}\end{array}$} \\
\hline & NH & SH & Globe & NH & SH & Globe & NH & SH & Globe \\
\hline IE & 44.4 & 44.5 & 88.9 & 173.2 & 174.0 & 173.6 & -5.6 & 3.4 & -1.1 \\
\hline PE & 16.8 & 16.6 & 33.4 & 65.6 & 65.0 & 65.3 & -2.0 & 1.1 & -0.5 \\
\hline LH & 1.59 & 1.55 & 3.14 & 6.20 & 6.05 & 6.13 & -3.12 & 1.89 & -0.62 \\
\hline$K \dagger$ & 0.028 & 0.032 & 0.061 & 0.111 & 0.125 & 0.118 & 0.101 & -0.051 & 0.026 \\
\hline$E$ & 62.8 & 62.7 & 125.5 & 245.1 & 245.2 & 245.1 & -10.6 & 6.3 & -2.2 \\
\hline
\end{tabular}

$\mathrm{NH}$, northern hemisphere; $\mathrm{SH}$, southern hemisphere; IE, internal energy; PE, potential energy; LH, latent heat; $K$, kinetic energy; $E$, total energy.

*Present values are about $5 \%$ smaller than the values reported by Oort and Peixóto [1983].

$\dagger$ Probably underestimated in the southern hemisphere by about $30 \%$.

\section{Data Sources and Data Analyses}

\subsection{Atmospheric Data}

The atmospheric energy integrals are based on daily reports from the global rawinsonde network for the 10-year period from May 1963 through April 1973. After careful checking, various monthly mean statistics were computed for each of the 700 to 800 rawinsonde stations at 11 levels in the vertical between the surface and 50-mbar (about $20 \mathrm{~km}$ ) height. Next, these station statistics were objectively analyzed onto a regular $2.5^{\circ}$ latitude by $5^{\circ}$ longitude grid [Oort, 1983].

The global fields of annual mean temperature $\langle T\rangle$ were then used in the present study (see also Oort and Peixóto [1983]) to compute the mean and stationary eddy available potential energy components $\boldsymbol{P}_{M}$ and $\boldsymbol{P}_{S E}$, and the fields of temperature variance $\left\langle T^{\prime 2}\right\rangle$ were used to compute the transient eddy available potential energy. Similarly, the global mean wind fields $\langle u\rangle$ and $\langle v\rangle$ were used to compute the mean and stationary eddy kinetic energy components $K_{M}$ and $K_{\text {SE }}$, and the wind variance fields $\left\langle u^{\prime 2}\right\rangle$ and $\left\langle v^{\prime 2}\right\rangle$ were used to compute the transient eddy kinetic energy.

\subsection{Oceanic Data}

The oceanic energy integrals are based mainly on an extensive global set containing about 500,000 historical hydrographic station data for temperature and salinity, about 785,000 mechanical bathythermograph soundings, and about 300,000 expendable bathythermograph soundings. All soundings were carefully checked and edited, and the mean temperature and salinity statistics were objectively analyzed onto a $1^{\circ}$ latitude by $1^{\circ}$ longitude grid at 33 levels between the surface and 5500-m depth [Levitus, 1982].

In order to evaluate the available gravitational potential energy in the oceans as given by (10), we needed first of all to obtain the density structure in the oceans. We computed the density with the Knudsen-Ekman equation of state as given by Fofonoff [1962], following Levitus [1982]. These density fields were then used to evaluate the mean and stationary eddy components of the available potential energy, $P_{M}$ and $P_{S E}$ from (10). The actual procedure for calculating the mean static stability $-\delta\langle\tilde{\rho}\rangle / d z$ in the expression for the available potential energy is given by Levitus [1982, p. 23].

Direct computations of the transient eddy available potential energy and the kinetic energy components could only be made at the ocean surface based on surface ship reports. To do this we made use of the so-called comprehensive oceanatmosphere data set (COADS) [Slutz et al., 1985; Woodruff et al., 1987] and of a surface ship drift data set [Stidd, 1975, Meehl, 1980]. From the COADS we computed the temperature variance $\left\langle T^{\prime 2}\right\rangle$ and then estimated the density variance $\left\langle\rho^{\prime 2}\right\rangle$, neglecting effects due to changes in salinity as we will describe in more detail later. This provided the surface contribution to the transient eddy available potential energy $P_{T E}$. The ship drift data enabled us to estimate the surface currents and provided the mean current values $\langle u\rangle$ and $\langle v\rangle$ as well as the current variances $\left\langle u^{\prime 2}\right\rangle$ and $\left\langle v^{\prime 2}\right\rangle$. Thus we were able to estimate the surface contributions to the kinetic energy integrals in $K_{M}, K_{S E}$, and $K_{T E}$. Some drift buoy estimates from the First GARP Global Experiment (FGGE) as analyzed by Piola et al. [1987] were used to estimate the kinetic energy at the high southern latitudes between $43^{\circ}$ and $59^{\circ} \mathrm{S}$, where there are only very few ship drift observations available. Assuming a decrease with depth of the contribution to the total integrals based on a reasonable vertical structure of the time mean flow and of the mesoscale phenomena in the oceans, it was possible to give tentative estimates of the kinetic energy integrals for the entire world ocean, as we will discuss later. As we mentioned before, our crude estimates of the transient eddy components, $K_{T E}$ and $P_{T E}$, should include the effects of all eddies with time scales of less than 1 year, such as seasonal and mesoscale eddies.

Some physical characteristics of the atmosphere and of the breakdown of the world ocean, as used in the present study, are presented in Table 1. The table shows the surface area, the mean depth, and the mass of the various components of the climatic system.

\section{SOME ENERGy INTEGRALS For THE ATMOSPHERE AND OCEANS}

In order to put our present estimates of the available energy components into perspective, we shall present here some estimates of the total energy in the atmosphere-ocean system and of the breakdown of the total energy into its different forms. The results for the atmosphere are shown in Table 2 and those for the oceans in Table 3. The energy content is given both in the form of integrals and in the form of energy amounts per unit area.

For the atmosphere most of the energy is contained in the internal and potential energy as defined earlier by (1) and (2). As expected, the numerical estimates of IE and PE in Table 2 


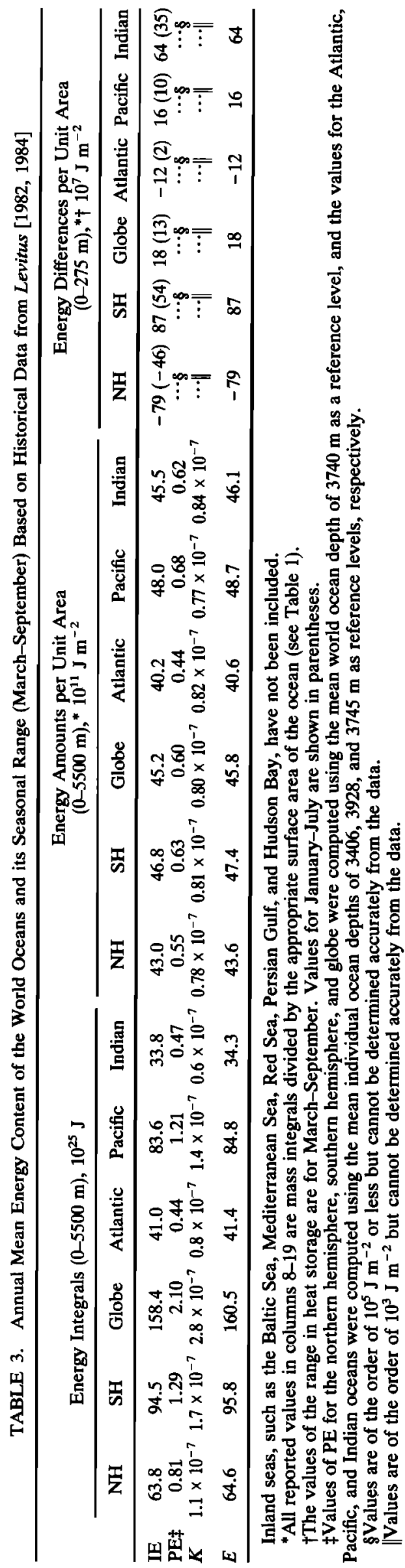

show the ratio IE/PE to be approximately equal to $c_{v} / R=$ $5 / 2$. The latent heat LH amounts to only about $2 \%$ of the total energy. The kinetic energy given by (12) is shown in the fourth row of Table 2. It is tiny, of the order of $0.05 \%$ of the total energy. The values in the two hemispheres are almost the same. In the last three columns the seasonal range in the energy components is shown through the January-July differences. The values for $\triangle \mathrm{IE}, \triangle \mathrm{PE}$, and $\Delta \mathrm{LH}$ are of the same magnitude, while the values for $\Delta K$ are more than one order of magnitude smaller. The predominance of the northern hemisphere is evident. These larger seasonal contrasts in the atmosphere of the northern hemisphere are, of course, related to the greater continentality in that hemisphere.

The energy amounts in the oceans are presented in Table 3. The estimates constitute a first attempt to give an integrated view of the energetics of the oceans. It is important to stress the limitations of our scheme for computing the kinetic energy mainly regarding the extrapolation to subsurface levels, which will be further discussed later. In Table 3 the values of the internal energy given by (6) dominate by far, and those of the potential energy given by (7) are only of the order of $1 \%$ of the total energy. The tentative kinetic energy estimates (excluding high-frequency wave motions) are almost a factor of a billion $\left(10^{-9}\right)$ smaller than the total energy. Because of the longer seasonal lag in the oceans, the March-September differences are presented in Table 3 as a more representative measure of the seasonal range. For a direct comparison with the atmosphere, the January-July differences are shown also (in parentheses). The seasonal range in oceanic energy is practically completely determined by the range in internal energy.

Comparisons of the oceanic and atmospheric values in Tables 2 and 3 show an annual mean value of $1605 \times 10^{24} \mathrm{~J}$ for the total potential plus internal energy in the oceans and a value of $1.3 \times 10^{24} \mathrm{~J}$, i.e., a factor of $1000 \mathrm{smaller}$, for the total energy in the atmosphere. On the other hand, the kinetic energy for the oceans is estimated to be only of the order of $0.03 \times 10^{20} \mathrm{~J}$ compared with an atmospheric value of 6.1 $\times 10^{20} \mathrm{~J}$, i.e., a factor of 200 smaller. The seasonal range values for the total energy per unit area for the northern hemisphere are $-79 \times 10^{7} \mathrm{~J} \mathrm{~m}^{-2}$ for the oceans and $-10.6 \times 10^{7} \mathrm{~J} \mathrm{~m}^{-2}$ for the atmosphere. Similarly, for the globe as a whole the difference in heat storage is greater for the oceans $\left(18 \times 10^{7} \mathrm{~J} \mathrm{~m}^{-2}\right)$ than for the atmosphere $(-2.2$ $\times 10^{7} \mathrm{~J} \mathrm{~m}^{-2}$ ). Neglecting other small terms, such as the energy storage in the cryosphere, the combined MarchSeptember difference of about $17 \times 10^{7} \mathrm{~J} \mathrm{~m}^{-2}$ for the energy storage in the ocean-atmosphere system must be balanced by the net radiational heating at the top of the atmosphere integrated over the half year between September and March. This last value is estimated to be $13 \times 10^{7} \mathrm{~J} \mathrm{~m}^{-2}$ using the direct satellite observations of the solar minus terrestrial radiation given by Ellis et al. [1978]. The two independent estimates of the seasonal range in energy storage of the Earth are in surprisingly good agreement, considering the sparseness of the heat storage data in the southern oceans and the possible systematic errors in the satellite observations.

\section{Distribution of the Available Potential aNd Kinetic ENERgy IN THE OCEANS}

On the basis of (10) and (16) we can evaluate two components of the available gravitational potential energy, namely, the mean zonal and the stationary eddy energy components, $\boldsymbol{P}_{M}$ and $\boldsymbol{P}_{S E}$. As we have stressed before, the number of subsur- 


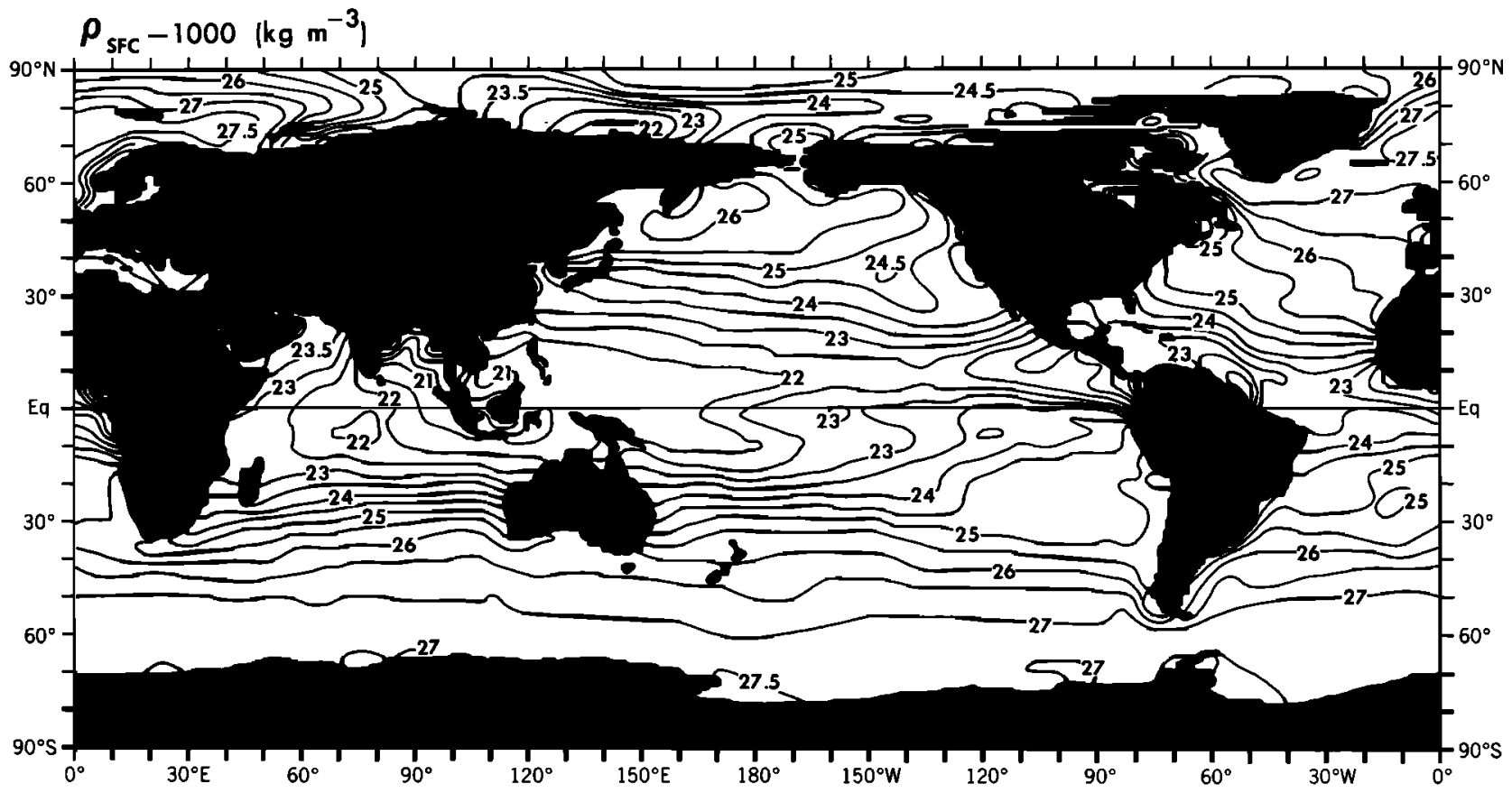

Fig. 2a. Global distribution of the annual mean surface density $\rho_{\text {sfc }}$ (actually shown, $\rho_{\text {sfc }}-1000$ ) in units of kilograms per cubic meter.

face density data is not sufficient to give a reliable estimate of the third component, the transient eddy energy $P_{\text {TE. }}$ Thus the values of $P_{T E}$ have to be used with caution and only as crude order of magnitude estimate.

\subsection{Density Distribution in the Oceans}

The horizontal distributions of the annual mean in situ density at the surface and at 500-m depth are shown in Figures $2 a$ and $2 b$ in terms of $(\rho-1000)$ and in units of kilograms per cubic meter. We may note that the density changes with depth due to compressibility are far larger than the changes due to thermal expansion or saline contraction for the range of temperatures and salinities observed in the world ocean. At the surface, both temperature and salinity variations contribute about equally to the overall variability. Thus a change in density of $\Delta \rho=0.25 \mathrm{~kg} \mathrm{~m}^{-3}$ at $15^{\circ} \mathrm{C}$ can be due to a change in temperature of about $\Delta T=1^{\circ} \mathrm{C}$, a change in salinity of about $\Delta S=0.3 \%$ or, of course, a combination of these two effects. The surface map in Figure $2 a$ shows a general increase

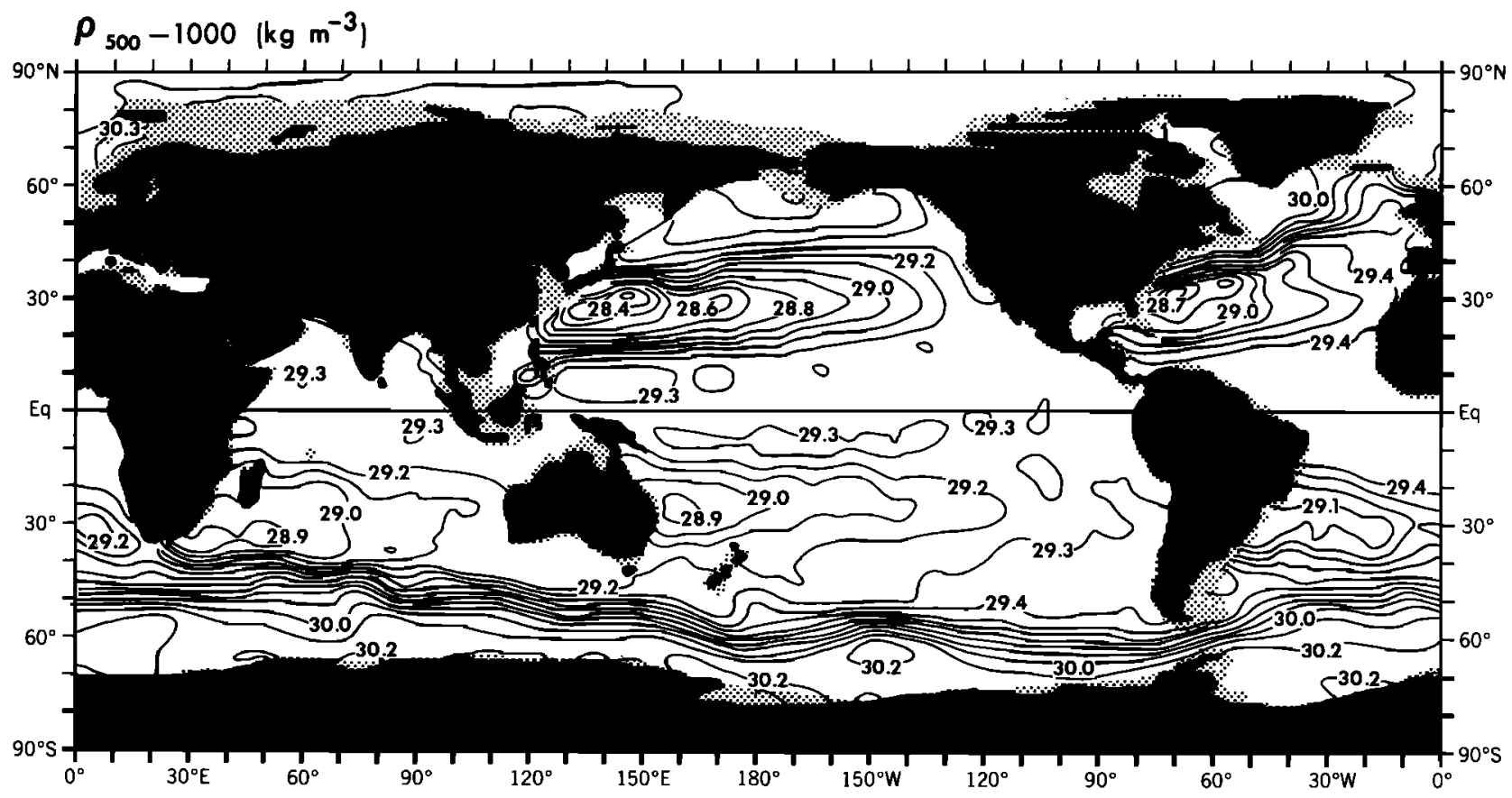

Fig. $2 b$. Global distribution of the annual mean density (actually shown, $\rho_{500}-1000$ ) at $500-m$ depth in units of kilograms per cubic meter. 


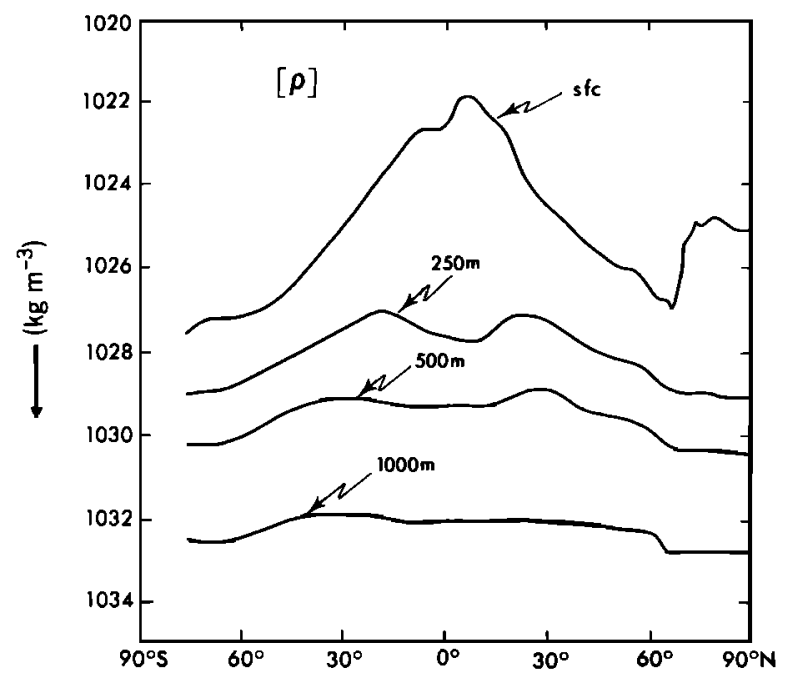

Fig. 3. Meridional profiles of annual mean in situ density at various depths.

of density with latitude with a minimum of $1022 \mathrm{~kg} \mathrm{~m}^{-3}$ or less under the Intertropical Convergence Zone and maximum values of $1027 \mathrm{~kg} \mathrm{~m}^{-3}$ or greater at high southern latitudes near Antarctica and in the most northern section of the Atlantic Ocean to the east of Greenland. In the Arctic Ocean the density is again less owing to the low salinities associated with the inflow of fresh water from rivers resulting in a shallow halocline.

At $500-\mathrm{m}$ depth in Figure $2 b$, the equatorial surface minimum has disappeared, and instead a minimum zone appears near $30^{\circ}$ latitude in each hemisphere with lowest values between about 1028.3 and $1028.7 \mathrm{~kg} \mathrm{~m}^{-3}$ just east of the continents. Maximum densities with values of about $1030.2 \mathrm{~kg} \mathrm{~m}^{-3}$ are found at high latitudes of both hemispheres. The horizontal gradients in density are about a factor of 5 smaller at this level than near the surface.

Meridional profiles of the zonal mean density for the global ocean at various depths are shown in Figure 3. The profiles bring out more clearly the rapid decrease of the density variations with depth. Below $1000 \mathrm{~m}$ the horizontal density gradients are considerably weaker than those near the surface. Thus we can expect the main contribution to the available gravitational potential energy to come from the first few hundred meters. In the meridional profiles some inland waters and seas have been excluded, such as Hudson Bay, the Baltic Sea, the Mediterranean Sea, the Red Sea and the Persian Gulf, because they have very different salinities and densities from the neighboring oceans and are generally disconnected from the main ocean circulation.

Finally the vertical profile of the global mean in situ density is presented in Figure 4. As in Figure 3 the inland seas have

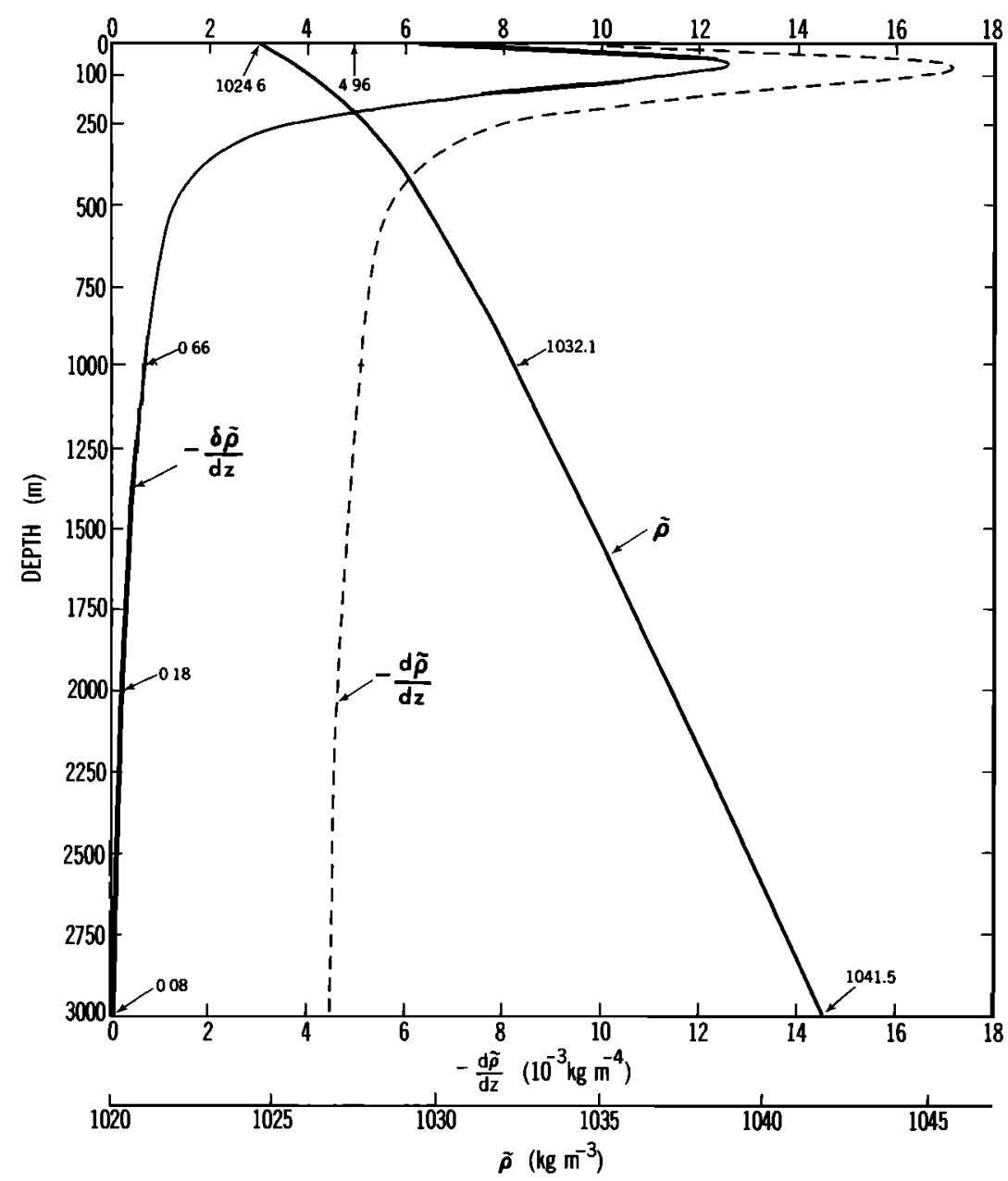

Fig. 4. Vertical profiles of the annual and global mean density, and two measures of the mean static stability (see text) in units of kilograms per cubic meter and $10^{-3} \mathrm{~kg} \mathrm{~m}^{-4}$, respectively. 


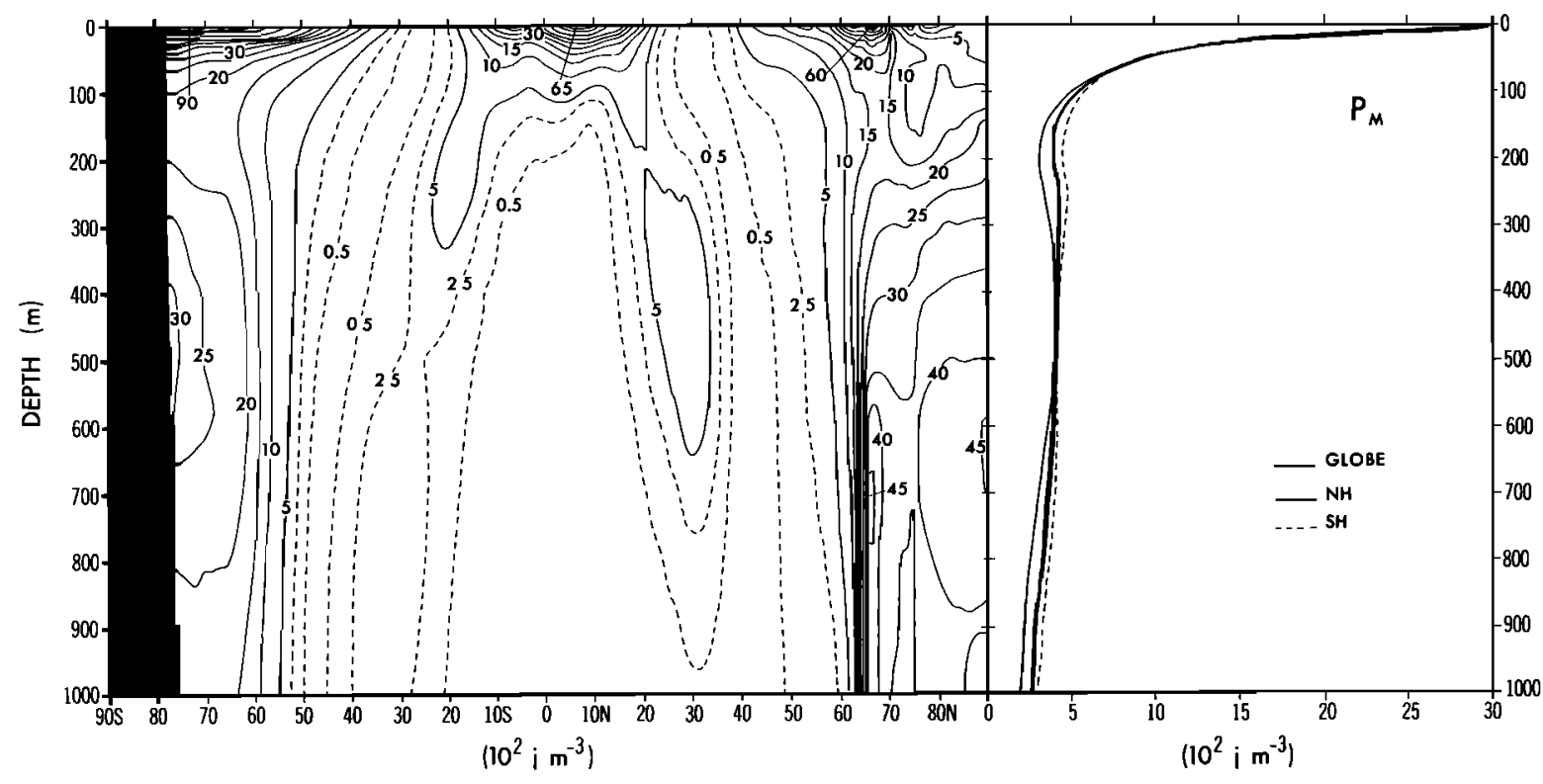

Fig. 5a. Zonal mean latitude-depth cross section of the integrand of the mean available gravitational potential energy $P_{M}$ for annual mean conditions in units of $10^{2} \mathrm{~J} \mathrm{~m}^{-3}$. Hemispheric and global mean profiles are added on the right-hand side of the diagram.

been excluded in computing the averages. The density increases from a mean value of about $1025 \mathrm{~kg} \mathrm{~m}^{-3}$ at the surface to about $1032 \mathrm{~kg} \mathrm{~m}^{-3}$ at $1000-\mathrm{m}$ depth and to about $1041 \mathrm{~kg} \mathrm{~m}^{-3}$ at $3000-\mathrm{m}$ depth, showing clearly the effects of the compressibility of seawater.

Two measures of the mean static stability are also shown in Figure 4 . The first measure, $-d \tilde{\rho} / d z$, is the vertical gradient of the global mean in situ density. It shows a very high value of the stability in the first few hundred meters, which probably reflects the presence of the seasonal thermocline in our data. However, this parameter is not a suitable measure of the stability below the surface layer, since compressibility effects are still included. As we have noted before, the second measure of stability, $-\delta \tilde{\rho} / d z$, is a correct measure to use in the available potential energy, where the symbolic expression $\delta \tilde{\rho} / d z$ indicates individual changes in density rather than geometric changes with depth [Neumann and Pierson, 1966, p. 139].

\subsection{Computations of $\boldsymbol{P}_{\boldsymbol{M}}$ and $\boldsymbol{P}_{\mathrm{SE}}$}

Using the mean density data described in the previous section various integrals have been evaluated. Zonal mean values of the integrands across the entire world ocean are presented in Figures $5 a$ and $5 b$ in units of $10^{2} \mathrm{~J} \mathrm{~m}^{-3}$. Some dashed contours are added to show the relatively weak spatial variations in the deeper layers. At the surface, the values of $P_{M}$ range from two high-latitude maxima of about $6000 \mathrm{~J} \mathrm{~m}^{-3}$ near $65^{\circ} \mathrm{N}$ and about $9000 \mathrm{~J} \mathrm{~m}^{-3}$ near $75^{\circ} \mathrm{S}$ to subtropical minima near $32^{\circ} \mathrm{N}$ and $28^{\circ} \mathrm{S}$, reaching a second maximum of about $6500 \mathrm{~J} \mathrm{~m}^{-3}$ near $8^{\circ} \mathrm{N}$. The occurrence of a minimum near the subtropics of each hemisphere is to be expected, since the density has to be equal to the global average density somewhere in between the equator and each pole, so that $\rho \approx \tilde{\rho}$. The figures show in the tropics a rapid decrease of the value of the integrand with depth. However, poleward of $60^{\circ}$ latitude there appear some strong maxima between about 500 and 1000-m depth. The occurrence of a wedge of maximum contribution near $20^{\circ}$ latitude at 200-m depth and near $30^{\circ}$ latitude at $800-\mathrm{m}$ depth in each hemisphere is mainly a reflec- tion of the temperature structure in the oceans. These are latitudes where the main thermocline has its deepest penetration.

The values of the integrand of the stationary eddy component $\boldsymbol{P}_{S E}$ shown in Figure $5 b$ are much smaller in general than those of the mean component $\boldsymbol{P}_{\boldsymbol{M}}$. A surface maximum value of about $3800 \mathrm{~J} \mathrm{~m}^{-3}$ is found near $73^{\circ} \mathrm{N}$, but almost everywhere else the contribution to $P_{S E}$ is $1000 \mathrm{~J} \mathrm{~m}^{-3}$ or less. The near-surface maximum at $73^{\circ} \mathrm{N}$ is due to the low-density waters associated with local runoff from the Siberian and North American rivers. The rate of decrease with depth is somewhat smaller for $\boldsymbol{P}_{S E}$ than for $\boldsymbol{P}_{\boldsymbol{M}}$.

Vertical profiles of the hemispheric and global mean values of $P_{M}$ and $P_{S E}$ are shown at the right-hand side of Figures $5 a$ and $5 b$ and in Table 4. These profiles show a rapid decrease of the integrands with depth in the first $100 \mathrm{~m}$ and a much slower decrease below that level. In fact, if we consider the vertical profiles down to $3000 \mathrm{~m}$ depth as shown in Figure 6 for the globe and the individual oceans, we notice that the values of the integrand of both $P_{M}$ and $P_{S E}$ show a slow increase with depth between 2000- and 3000-m depth. Thus if we compare the integrals between the surface and $1000-\mathrm{m}$ depth with those between the surface and $3000-\mathrm{m}$ depth, we find a doubling of the available gravitational potential energy, as is indicated in the bottom two rows of Table 4 .

Meridional profiles of the vertical integrals of $P_{M}+P_{S E}$, $P_{M}$, and $P_{S E}$ for three layers between the surface and various depths are shown in Figure 7. The profiles show that the upper 500-m layer gives the major contributions to the integrals in both $P_{M}$ and $P_{S E}$. We note again that with the exception of the intertropical regions the values of $P_{M}$ are much larger than those of $\boldsymbol{P}_{S E}$. The apparent importance of the Arctic contribution to $P_{M}$ is not real; it is caused by the use of a linear latitudinal scale that distorts the true contributions on the sphere. In fact, the contributions of the polar regions are relatively small, since in any volume integrals they will be weighted by the cosine of the latitude.

Finally, the mean annual hemispheric and global integrals 


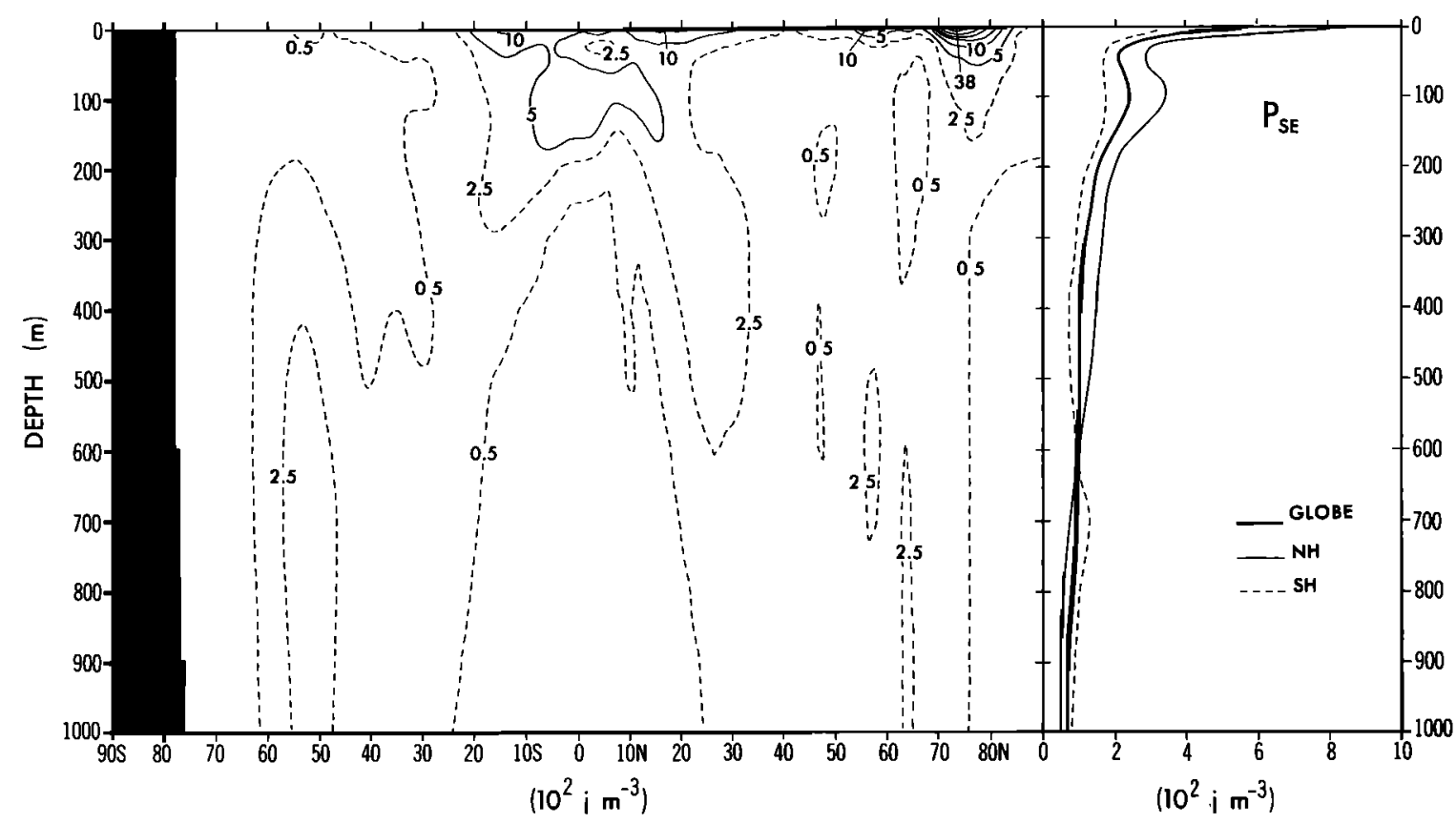

Fig. $5 b$. Same as Figure $5 a$ except for the stationary eddy gravitational potential energy $P_{S E}$.

are presented in Table 5 for the layer from the surface to 1000-m depth. It seems that $\boldsymbol{P}_{M}$ is somewhat larger in the southern hemisphere than in the northern hemisphere owing to the larger meridional variation of $[\rho]$ in the southern hemisphere. On the other hand, the $P_{S E}$ values (in terms of energy per unit area) are slightly smaller in the southern hemisphere because of the smaller east-west variance in density in the southern oceans with their greater uniformity and interconnectedness. The relative contribution of $P_{S E}$ to the total is about $20 \%$.

So far the reference state was defined using data for the entire world ocean. We have also made some computations for each ocean basin separately using the corresponding individual reference states. When expressed in energy per unit area, the resulting values of $\boldsymbol{P}_{M}$ for the Atlantic and Indian Oceans are appreciably larger than the global mean values, whereas they are smaller for the Pacific Ocean. These differences are largely due to the inclusion of more high-latitude regions in the Atlantic and Indian Oceans, which show greater temperature contrasts with the tropical regions and thereby lead to increased contributions to $P_{M}$.
The values of $P_{S E}$ for the individual oceans using again their particular reference state in Table 5 give values of about half of the global estimates. This fact is associated with the sizeable differences in the zonal mean values of density, i.e., in the reference state, at the same latitude between the three oceans.

\subsection{Estimates of $\boldsymbol{P}_{T E}$}

As was mentioned before, no estimates of the transient eddy available potential energy $P_{T E}$ have been made on a global basis because of the lack of adequate subsurface temperature and salinity data. However, an estimate can be made at the surface using the sea surface temperature observations from commercial ship reports if transient salinity effects on the density are neglected. This last assumption may not be correct, but it seems that we can use it to get some idea of the order of magnitude of $\boldsymbol{P}_{T E}$. In fact, using the linear approximation $\rho=$ $\rho_{0}(1-\alpha T)$ with $\rho_{0}=1029 \mathrm{~kg} \mathrm{~m}^{-3}$ and $\alpha=0.00025^{\circ} \mathrm{C}^{-1}$ we obtain an approximate expression for $\boldsymbol{P}_{T E}$ that is suitable for use with the available observed data:

TABLE 4. Values of the Integrand of the Available Gravitational Potential Energy in the World Ocean at Various Depths for Annual Mean Conditions

\begin{tabular}{|c|c|c|c|c|c|c|c|c|c|c|}
\hline & \multicolumn{3}{|c|}{$P_{M}$} & \multicolumn{3}{|c|}{$P_{S E}$} & \multicolumn{3}{|c|}{$\mathbf{P}_{\mathrm{TE}}{ }^{*}$} & \multirow[b]{2}{*}{ Units } \\
\hline & NH & SH & Globe & NH & SH & Globe & NH & SH & Globe & \\
\hline Surface & 2.74 & 2.92 & 2.84 & 0.86 & 0.37 & 0.57 & 0.33 & 0.16 & 0.23 & $10^{3} \mathrm{~J} \mathrm{~m}^{-3}$ \\
\hline $100 \mathrm{~m}$ & 0.47 & 0.57 & 0.53 & 0.34 & 0.18 & 0.24 & $\cdots$ & $\cdots$ & $\cdots$ & $10^{3} \mathrm{~J} \mathrm{~m}^{-3}$ \\
\hline $500 \mathrm{~m}$ & 0.40 & 0.40 & 0.40 & 0.13 & 0.08 & 0.10 & $\cdots$ & $\cdots$ & $\cdots$ & $10^{3} \mathrm{~J} \mathrm{~m}^{-3}$ \\
\hline $1000 \mathrm{~m}$ & 0.20 & 0.30 & 0.26 & 0.04 & 0.08 & 0.07 & $\cdots$ & $\cdots$ & $\cdots$ & $10^{3} \mathrm{~J} \mathrm{~m}^{-3}$ \\
\hline $2000 \mathrm{~m}$ & 0.28 & 0.17 & 0.21 & 0.10 & 0.06 & 0.07 & $\cdots$ & $\cdots$ & $\cdots$ & $10^{3} \mathrm{~J} \mathrm{~m}^{-3}$ \\
\hline $3000 \mathrm{~m}$ & 0.37 & 0.31 & 0.33 & 0.28 & 0.10 & 0.17 & $\cdots$ & $\cdots$ & $\cdots$ & $10^{3} \mathrm{~J} \mathrm{~m}^{-3}$ \\
\hline Integral $0-1000 \mathrm{~m}$ & 3.79 & 4.84 & 4.40 & 1.38 & 1.11 & 1.22 & 0.66 & 0.32 & 0.46 & $10^{5} \mathrm{~J} \mathrm{~m}^{-2}$ \\
\hline Integral $0-3000 \mathrm{~m}$ & 8.74 & 9.15 & 8.98 & 3.89 & 2.48 & 3.06 & & & & $10^{5} \mathrm{~J} \mathrm{~m}^{-2}$ \\
\hline
\end{tabular}

* Surface estimates of $P_{T E}$ are based on the annual mean temperature variance fields that include the (large) annual variation in temperature. If we exclude the annual variation in temperature, the surface estimates of $P_{T E}$ would be much lower, with values of $0.07,0.06$, and $0.06 \times 10^{3} \mathrm{~J} \mathrm{~m}^{-3}$ for the northern hemisphere, southern hemisphere, and globe, respectively. 

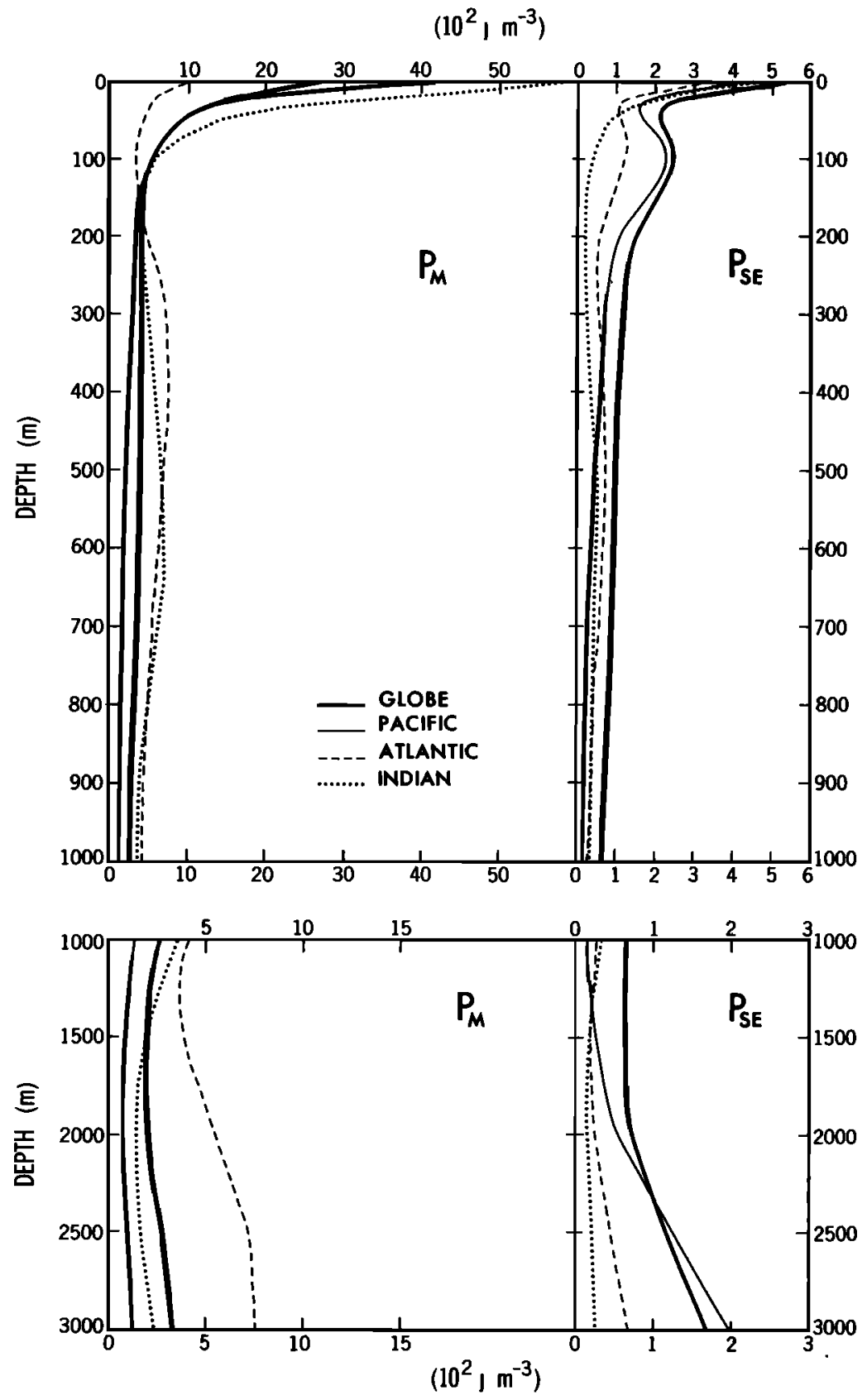

Fig. 6. Vertical profiles of the integrands of the mean and standing eddy available potential energy components, $\boldsymbol{P}_{M}$ and $P_{S E}$, averaged horizontally over the Pacific, Atlantic, Indian, and global oceans for annual mean conditions in $10^{2} \mathrm{~J}$ $\mathrm{m}^{-3}$. Note that the scales are different for the 0 - to $1000-\mathrm{m}$ and the 1000 - to $3000-\mathrm{m}$ layers.

$$
P_{T E}=-\frac{1}{2} \int \frac{g \rho_{0}{ }^{2}\left\langle\mathrm{~T}^{2}\right\rangle \alpha^{2}}{\delta\langle\tilde{\rho}\rangle / d z} d V
$$

Using the analyzed values of $\left\langle T^{2}\right\rangle$ (where the angle brackets indicate an annual average and the prime a departure from the annual mean value) at the surface, we can now estimate the average surface contribution to $P_{T E}$. The surface value for the globe turns out to be about $230 \mathrm{~J} \mathrm{~m}^{-3}$. Since no subsurface data are available for $\left\langle\mathrm{T}^{2}\right\rangle$, the total value for the oceans cannot be computed directly. We approximated the vertical integral in $P_{T E}$ by using a 200 -m-thick layer with a uniform value equal to the estimated surface value, where we assumed the contributions by the eddies to be significant. However, this choice is somewhat arbitrary. In this way we find in Table 4 for the layer 0 - to $1000-\mathrm{m}$ depth a global mean value of 0.46 $\times 10^{5} \mathrm{~J} \mathrm{~m}^{-2}$ for $P_{T E}$. For comparison, the hemispheric values are also presented in Tables 4 and 5 . Inspection of the different values seems to indicate that the contributions of the tentative values of $P_{T E}$ to the total available potential energy must be relatively small.

For the North Atlantic Ocean, Dantzler [1977] has been able to make some subsurface estimates of the transient eddy available potential energy based on a large sample of expendable bathythermograph data. He used the measured displacements of the $15^{\circ} \mathrm{C}$ isotherm in the alternative expression 


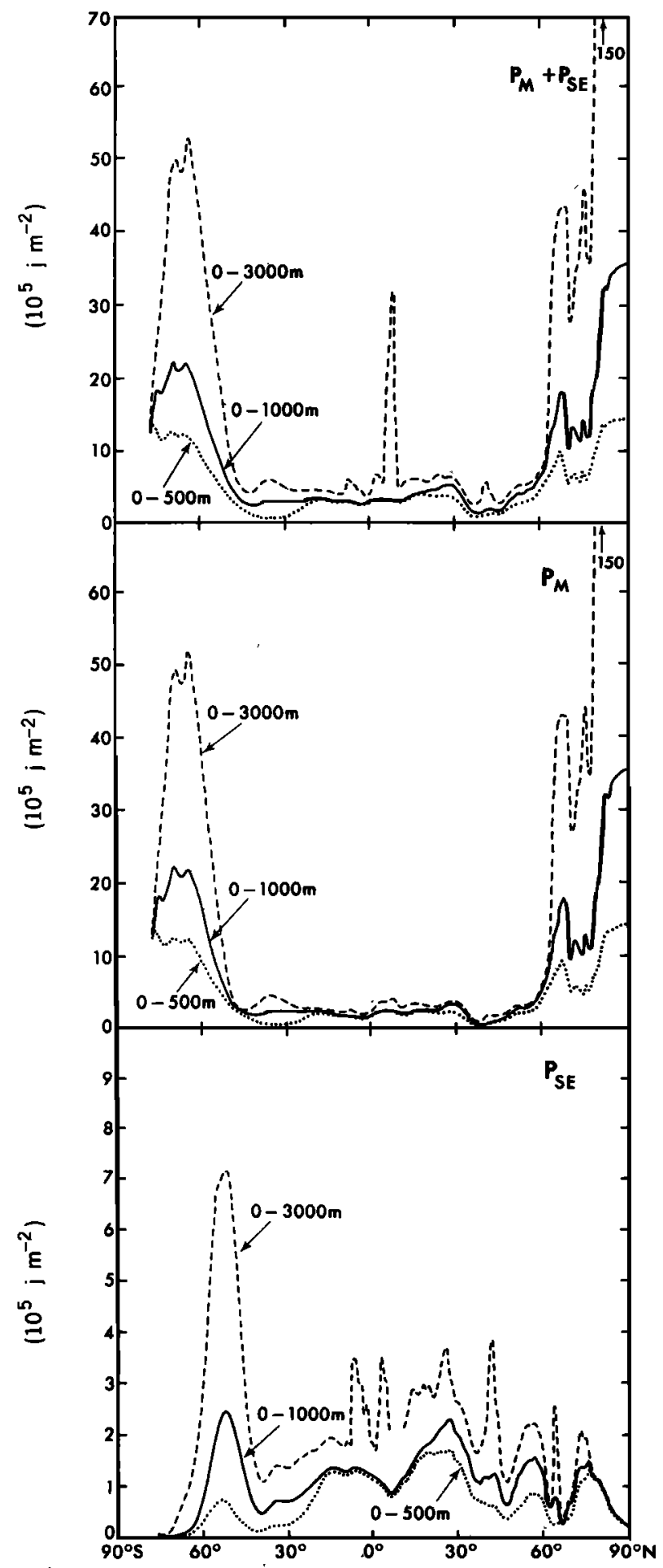

Fig. 7. Meridional profiles of the integrand of (top) $\boldsymbol{P}_{M}+\boldsymbol{P}_{S E}$ (middle) $P_{M}$, and (bottom) $P_{S E}$ for the three depth layers $0-500 \mathrm{~m}$, $0-1000 \mathrm{~m}$ and $0-3000 \mathrm{~m}$ in units of $10^{5} \mathrm{~J} \mathrm{~m}^{-2}$.

(9) for the available potential energy to estimate the transient eddy component $\boldsymbol{P}_{T E}$ in the main thermocline. Dantzler's work for the North Atlantic was updated and extended by Emery [1983] to include estimates for the North Pacific Ocean.

Using a value of $300 \mathrm{~cm}^{2} \mathrm{~s}^{-2}$ from Dantzler [1977] and Emery [1983] as being representative for a layer $200 \mathrm{~m}$ thick, we find a value of $0.06 \times 10^{5} \mathrm{~J} \mathrm{~m}^{-2}$ for $P_{T E}$ in the North Atlantic, which compares well with the global estimate in Table 4 based on the surface temperature variance, when we exclude the contribution of the annual cycle in temperature and include only time variations of less than 1 month.

\subsection{Estimates of $K_{M}, K_{S E}$, and $K_{T E}$}

An attempt was made to estimate the various modes of kinetic energy in the oceans using surface current data with (12) and (17). However, no subsurface values of the kinetic energy are available on the global scale, except for some time mean geostrophic estimates. Therefore in order to get some insight into the full energetics of the oceans it seemed, as a first attempt, important to get some preliminary estimates of the total kinetic energy based on real data. Thus on the basis of some knowledge of the vertical structure of the typical mesoscale eddies in the oceans we decided to use the surface data to obtain some representative values for the total kinetic energy assuming that their contributions can be represented by a layer $100 \mathrm{~m}$ thick. The meridional profiles are given in Figure 8, and the integrals are given in Table 5. It is obvious that these values should be taken as tentative first estimates. Nevertheless, they seem reasonable when compared with the global kinetic energy. value of $0.05 \times 10^{5} \mathrm{~J} \mathrm{~m}^{-2}$ that would result assuming an average ocean speed of $5 \mathrm{~cm} / \mathrm{s}$ for the entire mass of the world ocean. The curves in Figure 8 show that the kinetic energy is contained mainly in the transient eddy mode with a maximum in the equatorial regions and secondary maxima in subpolar regions. These results are very similar to those in the earlier study by Wyrtki et al. [1976]. In general, we may conclude that the relative importance of the various components of the kinetic energy is very different from that in the available potential energy, for which the mean component was of primary significance.

Our tentative annual mean estimates of $K_{T E}$ are a factor of 5 to 10 smaller than those for $\boldsymbol{P}_{T E}$. However, when we exclude the annual variation in the temperatures and currents, we find that the estimates of $K_{T E}$ and $P_{T E}$ are about equal, which is consistent with what one would expect for eddy scales of the order of the radius of deformation [Gill et al., 1974].

\section{Comparisons of the Available Potential AND Kinetic ENERgy Amounts In THE ATMOSPHERE AND OCEANS}

In order to get some insight regarding the differences in available gravitational potential energy for the atmosphere and oceans, we will compare the various factors that enter into expression (10) for $P$ (see also Wells [1986, p. 263]). For this purpose let us take for the atmospheric density variations a typical value of

$$
\rho-\tilde{\rho} \sim 10^{-1} \mathrm{~kg} \mathrm{~m}^{-3}
$$

and for the mean stability throughout the depth of the atmosphere $(\sim 10,000 \mathrm{~m})$ a value of

$$
-\frac{\delta \tilde{\rho}}{d z} \sim 10^{-4} \mathrm{~kg} \mathrm{~m}^{-4}
$$

For the corresponding oceanic parameters we will assume in the upper $200 \mathrm{~m}$ layer, where most of the activity occurs, a 
TABLE 5. Estimates of the Annual Mean Available Gravitational Potential and Kinetic Energy Components in the World Oceans

\begin{tabular}{|c|c|c|c|c|c|c|c|c|c|c|c|c|}
\hline & \multicolumn{6}{|c|}{ Energy Integrals, $10^{20} \mathrm{~J}$} & \multicolumn{6}{|c|}{ Energy per Unit Area, ${ }^{*} 10^{5} \mathrm{~J} \mathrm{~m}^{-2}$} \\
\hline & NH & SH & Globe & Atlantic & Pacific & Indian & NH & SH & Globe & Atlantic & Pacific & Indian \\
\hline & & & & & & Potential & & & & & & \\
\hline $\boldsymbol{P}_{M}$ & 0.56 & 0.99 & 1.55 & $0.52 \dagger$ & $0.59 \dagger$ & $0.52 \dagger$ & 3.79 & 4.84 & 4.40 & $5.21 \dagger$ & $3.34 \dagger$ & $6.90 \dagger$ \\
\hline$P_{S E}$ & 0.20 & 0.23 & 0.43 & $0.06 \dagger$ & $0.13 \dagger$ & $0.04 \dagger$ & 1.38 & 1.11 & 1.22 & $0.60 \dagger$ & $0.72 \dagger$ & $0.47 \dagger$ \\
\hline$P_{T E} \ddagger$ & 0.10 & 0.07 & 0.16 & $\cdots$ & $\cdots$ & $\cdots$ & 0.66 & 0.32 & 0.46 & $\cdots$ & $\cdots$ & $\cdots$ \\
\hline$P^{x}$ & 0.86 & 1.29 & 2.14 & $0.58 \dagger$ & $0.72 \dagger$ & $0.56 \dagger$ & 5.83 & 6.27 & 6.08 & $5.82 \dagger$ & $4.06 \dagger$ & $7.37 \dagger$ \\
\hline$K_{M} \S$ & & & & 0001 & 0001 & Kinetic & 0004 & $0 \mathrm{M7}$ & & 000 & & 0006 \\
\hline$K_{S E}^{M} \S$ & 0.001 & 0.001 & 0.002 & $<0.001$ & 0.001 & $<0.001$ & 0.005 & 0.005 & 0.005 & $\begin{array}{l}0.004 \\
0.004\end{array}$ & $\begin{array}{l}0.007 \\
0.003\end{array}$ & $\begin{array}{l}0.000 \\
0.003\end{array}$ \\
\hline$K_{T E} \S$ & 0.010 & 0.014 & 0.025 & 0.007 & 0.012 & 0.006 & 0.070 & 0.069 & 0.070 & 0.070 & 0.067 & 0.075 \\
\hline$K \S$ & 0.011 & 0.017 & 0.028 & 0.008 & 0.014 & 0.006 & 0.078 & 0.081 & 0.080 & 0.082 & 0.077 & 0.084 \\
\hline
\end{tabular}

Inland seas, such as the Baltic Sea, Mediterranean Sea, Red Sea, Persian Gulf and Hudson Bay, have not been included. The estimates of $P_{T E}, K_{M}, K_{S E}, K_{T E}$, and $K$ are tentative (see text). The estimates of $P_{M}$ and $P_{S E}$ were made for the 0 - to 1000-m depth layer.

*Values are integrals over total ocean mass divided by appropriate surface area of the ocean (see Table 1).

$\dagger$ Values are based on a different reference state $\bar{\rho}(z)$ for each ocean where $\bar{\rho}(z)$ is the average density over the ocean basin at depth $z$ (note that the northern hemisphere, southern hemisphere, and global values were all computed using the same reference state for the world ocean).

$\ddagger$ Values of $\boldsymbol{P}_{T E}$ were estimated by multiplying the surface contribution by a thickness of $200 \mathrm{~m}$.

$\S$ Values of $K, K_{M}, K_{S E}$, and $K_{T E}$ were estimated by multiplying the surface contribution from ship drift and drifting buoy data by a thickness of $100 \mathrm{~m}$.

typical value

$$
\rho-\tilde{\rho} \sim 2 \mathbf{k g ~ m}^{-3}
$$

and for the mean stability (see Figure 4) we will take a value

$$
-\frac{\delta \tilde{\rho}}{d z} \sim 0.8 \times 10^{-2} \mathrm{~kg} \mathrm{~m}^{-4}
$$

Using these estimates, we obtain for the ratio of the total available potential energy in the ocean and atmosphere a value of $1 / 10$. These estimates show that the two most important factors that explain the small ratio, $P^{O} / P^{A}$, are the larger stability of the oceans and the smaller oceanic depth range $\Delta z$ in which the active processes take place. These two factors overcome the larger observed density variations in the oceans compared with those in the atmosphere.

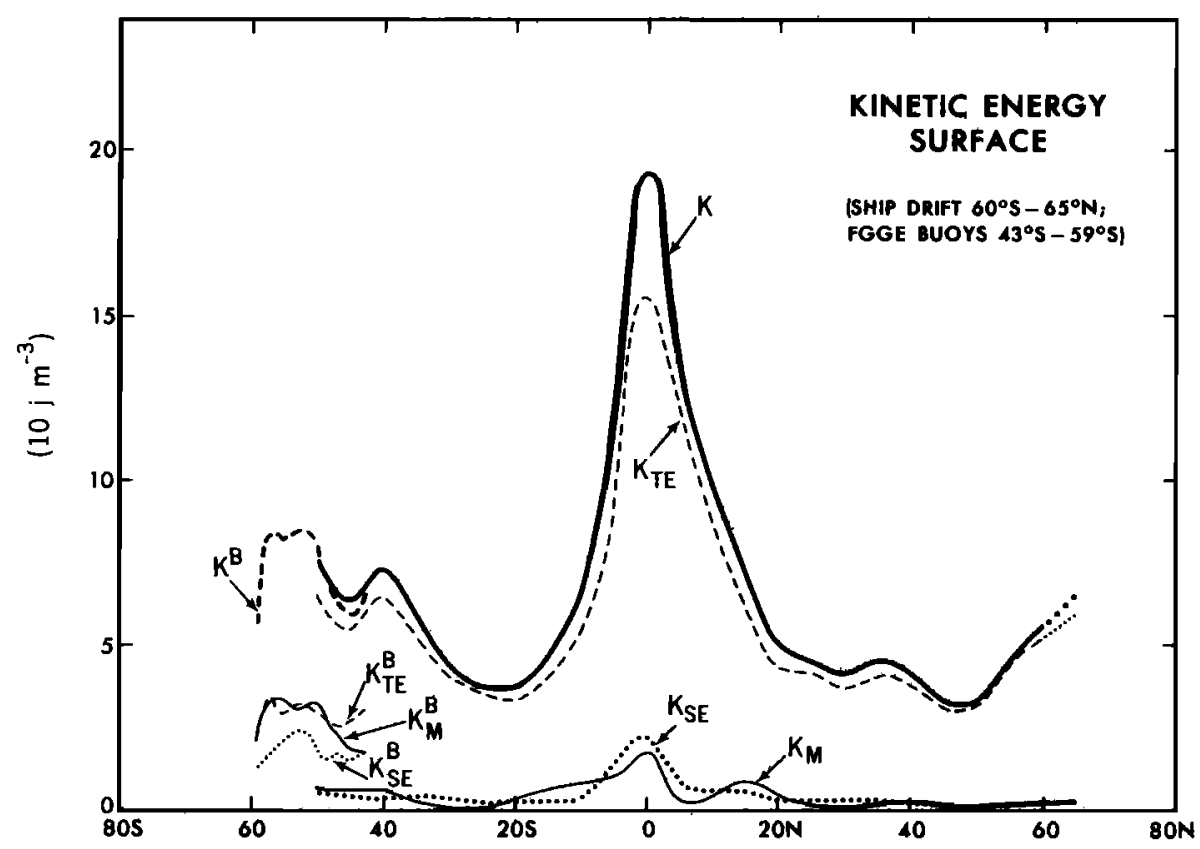

Fig. 8. Meridional profiles of the surface kinetic energy $K$ and its mean, stationary eddy and transient eddy components $\left(K_{M}, K_{S E}, K_{T E}\right)$ based on ship drift data. The ship drift data north of $60^{\circ} \mathrm{N}$ and south of $50^{\circ} \mathrm{S}$ are unreliable, since they are based on very few observations. Some recent results from buoy data (indicated by a superscript $B$ ) are included south of $44^{\circ} \mathrm{S}$ for completeness [Piola et al., 1987]. 
TABLE 6. Estimates of the Available Potential and Kinetic Energy in the Atmosphere for Annual Mean Conditions

\begin{tabular}{|c|c|c|c|c|c|c|}
\hline & \multicolumn{3}{|c|}{ Energy Integrals, $10^{20} \mathrm{~J}$} & \multicolumn{3}{|c|}{$\begin{array}{l}\text { Energy per Unit Area,* } \\
\qquad 10^{5} \mathrm{~J} \mathrm{~m}^{-2}\end{array}$} \\
\hline & NH & SH & Globe & NH & SH & Globe \\
\hline \multicolumn{7}{|c|}{ Potential ${ }^{\dagger}$} \\
\hline$P_{M}$ & 8.1 & 9.0 & 17.0 & 31.5 & 35.1 & 33.3 \\
\hline$P_{S E}$ & 0.31 & 0.10 & 0.41 & 1.2 & 0.4 & 0.8 \\
\hline$P_{T E}^{\Delta E}$ & 3.1 & 2.2 & 5.3 & 12.1 & 8.6 & 10.3 \\
\hline$P$ & 11.5 & 11.3 & 22.7 & 44.8 & 44.1 & 44.4 \\
\hline \multicolumn{7}{|c|}{ Kinetic $¥$} \\
\hline$K_{M}$ & 0.9 & 1.4 & 2.3 & 3.6 & 5.5 & 4.5 \\
\hline$K_{S E}$ & 0.1 & 0.1 & 0.2 & 0.6 & 0.3 & 0.4 \\
\hline$K_{T E}$ & 1.8 & 1.7 & 3.5 & 6.9 & 6.8 & 6.9 \\
\hline$K$ & 2.8 & 3.2 & 6.1 & 11.1 & 12.5 & 11.8 \\
\hline
\end{tabular}

†Values of available potential energy are 5-10\% smaller than those reported by Oort and Peixóto [1983] owing mainly to the present use of slightly smaller values for the static stability $\boldsymbol{\gamma}$.

¥Values of kinetic energy are about $5 \%$ smaller than values reported by Oort and Peixoto [1983].

"Values are integrals over total atmospheric mass divided by the appropriate surface area of the northern hemisphere, southern hemisphere, and globe, namely $2.56,2.56$, and $5.12 \times 10^{14} \mathrm{~m}^{2}$, respectively.

More detailed comparisons of the ocean-atmosphere energy amounts are possible using the actual oceanic values from Table 5, and the atmospheric values presented in Table 6 based on earlier estimates from Oort and Peixóto [1983]. The resulting ratios are given in Table 7 . Thus we find for the globe as a whole that

$$
\begin{gathered}
P^{o} / P^{A} \approx 0.09 \\
P_{M}^{o} / P_{M}^{A} \approx 0.09 \\
P_{S E}^{o} / P_{S E}^{A} \approx 1.0 \\
P_{T E}^{o} / P_{T E}^{A} \approx 0.03 \\
K^{o} / K^{A} \approx 0.005 \\
K_{T E}^{o} / K_{T E}^{A} \approx 0.007
\end{gathered}
$$

These ratios show that in terms of available potential and kinetic energy, the oceans are much less energetic than the atmosphere. In particular, the transient eddy kinetic and transient eddy available potential energy ratios show how much more turbulent the atmosphere is compared with the oceans.

Finally, comparing the kinetic energy-potential energy ratios for the globe in the two media we find the smaller value for the oceans:

$$
\begin{gathered}
(K / P)^{O} \approx 0.013 \\
(K / P)^{A} \approx 0.27
\end{gathered}
$$

\section{Some Final Comments}

Although our comparisons of the energetics of the oceans and atmosphere are preliminary in nature, there are some facts that stand out. We not only confirm the well-known role of the world ocean as the most important reservoir of heat in the climatic system (see Tables 2 and 3) but also give a measure of the seasonal range. Probably for the first time we have clearly documented the values of the available gravitational potential energy and the kinetic energy in the oceans and compared them with those in the atmosphere. From the relative smallness of the oceanic estimates, the ocean is seen as a comparatively passive medium driven largely by the highly turbulent atmosphere.

We have chosen to use our results for $P_{M}$ and $P_{S E}$ for the 0to $1000-m$ layer in the comparisons with the atmosphere although, as can be seen in Figure 6, the mean and standing eddy available potential energy are small but not negligible below 1000-m depth. For example, the integration down to 3000-m depth more than doubles the mean zonal available potential energy estimate for the global oceans from 4.4 to $9.0 \times 10^{5} \mathrm{~J} \mathrm{~m}^{-2}$.

As regards the reliability of the results, we may say that the basic density fields are reasonably well known, except in the data-sparse regions at high latitudes [Levitus, 1982]. Fortunately, these last contributions to the global energy integrals are relatively small. One way to evaluate the uncertainty in the computed values is by intercomparison of the integrals over the two hemispheres and the three oceans as presented in the tables and figures. However, the major uncertainty factor in the integrals appears to be connected with the depth to which one integrates, since the contributions below about 200 $m$ do not decrease much with depth, as is shown clearly in the vertical profiles of Figure 6. Our choice of the 0 - to $1000-\mathrm{m}$ layer is somewhat arbitrary, and other investigators might want to consider different layers depending to some extent on what oceanic processes they want to study.

In a later paper we intend to extend the present work to include the energy generation, conversion, and dissipation terms to elucidate the cycle of energy as shown earlier in the four-box diagram in Figure 1. Our preliminary estimates of the mechanical energy input by the winds and the energy

\begin{tabular}{|c|c|c|c|c|c|c|c|c|c|c|c|}
\hline & IE & PE & $E$ & $P_{M}$ & $\boldsymbol{P}_{S E}$ & $\boldsymbol{P}_{\boldsymbol{T E}}$ & $P$ & $\boldsymbol{K}_{M}$ & $\boldsymbol{K}_{S E}$ & $K_{T E}$ & $\boldsymbol{K}$ \\
\hline NH & 1440 & 48 & 1030 & 0.07 & 0.7 & 0.03 & 0.07 & 0.001 & 0.01 & 0.006 & 0.004 \\
\hline SH & 2120 & 78 & 1530 & 0.11 & 2.3 & 0.03 & 0.11 & 0.001 & 0.02 & 0.008 & 0.005 \\
\hline Globe & 1780 & 63 & 1280 & 0.09 & 1.0 & 0.03 & 0.09 & 0.001 & 0.01 & 0.007 & 0.005 \\
\hline
\end{tabular}
conversions give numbers of the order of $0.01 \mathrm{~W} \mathrm{~m} \mathrm{~m}^{-2}$. In comparison, the energy transformations between available potential and kinetic energy in the atmosphere are very much larger, i.e., of the order of 2 to $3 \mathrm{~W} \mathrm{~m} \mathrm{~m}^{-2}$ [Oort and Peixóto, 1983]. This confirms the picture of a less active ocean circulation.

TABLE 7. Ocean-Atmosphere Energy Ratios Based on Values in Tables 2, 3, 5, and 6 
Acknowledyments. The authors would like to thank Kirk Bryan and Mike Cox for their extensive reviews of the manuscript, Johann Callan and Joyce Kennedy for typing the manuscript, and Mel Rosenstein, Phil Tunison, Kathy Raphael, and John Conner for preparing the figures. The financial support of José P. Peixóto by the National Oceanic and Atmospheric Administration under grant NA84-EA-D00057 and of Stephen C. Ascher by the National Science Foundation under grant NSFATM8218761A01, while he was a student in the Undergraduate Summer Research Program of the Atmospheric and Oceanic Sciences Program at Princeton University, is gratefully acknowledged.

\section{REFERENCES}

Dantzler, H. L., Jr., Potential energy maxima in the tropical and subtropical North Atlantic, J. Phys. Oceanogr., 7, 512-519, 1977.

Ellis, J. S., T. H. Vonder Haar, S. Levitus, and A. H. Oort, The annual variation in the global heat balance of the Earth, J. Geophys. Res., $83,1958-1962,1978$.

Emery, W. J., On the geographical variability of the upper level mean and eddy fields in the North Atlantic and North Pacific, J. Phys. Oceanogr., 13, 269-291, 1983.

Folonoff, N. P., Physical properties of sea water, in The Sea, vol. 1, edited by M. N. Hill, pp. 3-30, Wiley-Interscience, New York, 1962.

Gill, A. E., J. S. A. Green, and A. J. Simmons, Energy partition in the large-scale ocean circulation and the production of mid-ocean eddies, Deep Sea Res., 21, 499-528, 1974.

Levitus, S., Climatological atlas of the world ocean, NOAA Prof. Pap. 13, 163 pp., 17 microfiches, U.S. Government Printing Office, Washington, D. C., 1982.

Levitus, $S$., Annual cycle of temperature and heat storage in the world ocean, J. Phys. Oceanogr., 14, 727-746, 1984.

Lorenz, E. N., Available potential energy and the maintenance of the general circulation, Tellus, 7, 157-167, 1955.

Lorenz, E. N., Available energy and the maintenance of a moist circulation, Tellus, 30, 15-31, 1978.

Margules, M., Ủber die Energie der Stürme, Jahrb. Zentralanst. Meteorol. Geodyn., 1-26, 1903. (English translation, The mechanics of the Earth's atmosphere, translated by C. Abbe, Smithson. Misc. Collect., 51, 553-593, 1910.)

Meehl, G. A., Observed world ocean seasonal surlace currents on a $5^{\circ}$ grid. NCAR Tech. Note TN/IA-159, 23 pp., Natl. Center for Atmos. Res., Boulder, Colo., 1980.
Neumann, G., and W. J. Pierson, Jr., Principles of Physical Oceanography, 545 pp., Prentice-Hall, Englewood Cliffs, N. J., 1966.

Oort, A. H., On estimates of the atmospheric energy cycle, Mon. Weather Rev., 92, 483-493, 1964.

Oort, A. H., Global atmospheric circulation statistics, 1958-1973, NOAA Prof. Pap. 14, 180 pp., 47 microfiches; U.S. Government Printing Ofice, Washington, D. C., 1983.

Oort, A. H., and J. P. Peixóto, Global angular momentum and energy balance requirements from observations, Adv. Geophys., 25, 355490, 1983.

Piola, A. R., H. A. Figueroa, and A. A. Bianchi, Some aspects of the surface circulation south of $20^{\circ} \mathrm{S}$ revealed by First GARP Global Experiment drifters, J. Geophys. Res., 92, 5101-5114, 1987.

Reid, R. O., B. A. Elliott, and D. B. Olson, Available potential energy: A clarification, J. Phys. Oceanogr., II, 15-29, 1981.

Slutz, R. J., S. J. Lubker, J. D. Hiscox, S. D. Woodruff, R. L. Jenne, D. H. Joseph, P. M. Steurer, and J. D. Elms, Comprehensive oceanatmosphere data set; Release 1, 268 pp., Clim. Res. Program, Environ. Res. Lab., NOAA, Boulder, Colo., 1985.

Stidd, C. K., Meridional profiles of ship drift components, J. Geophys. Res, $80,1679-1682,1975$.

Wells, N., The Atmosphere and Ocean: A Physical Introduction, 347 pp., Taylor and Francis, Philadelphia, Pa., 1986.

Woodruff, S. D., R. J. Slutz, R. L. Jenne, and P. M. Steurer, A comprehensive ocean-atmosphere data set, Bull. Am. Meteorol. Soc., 68, 1239-1250, 1987

Wyrtki, K., L. Magaard, and J. Hager, Eddy energy in the oceans, $J$. Geophys. Res., 81, 2641-2646, 1976.

S. C. Ascher, Department of Geology and Geophysics, Yale University, Box 6666, New Haven, CT 06511.

S. Levitus and A. H. Oort, Geophysical Fluid Dynamics Laboratory, NOAA, Princeton University, P. O. Box 308, Princeton, N. J. 08542.

J. P. Peixóto, Instituto Geofisico do Infante D. Luis, Rua da Escola Politecnica, 1200 Lisboa, Portugal.

(Received April 25, 1988

revised August 8, 1988 ;

accepted November 22, 1988.) 